\title{
Eutrophication, Oligotrophication, and Benthiphication in Naroch Lakes: 40 Years of Monitoring
}

\author{
Boris V. Adamovich*, Tatyana V. Zhukova, \\ Tamara M. Mikheyeva, Raisa Z. Kovalevskaya, \\ Tamara A. Makarevich and Anna A. Zhukova \\ Belarusian State University \\ 4 Nezavisimosty, Minsk, 220030, Belarus
}

Received 19.10.2016, received in revised form 04.07.2017, accepted 26.11.2017

Naroch lakes present a system of three interconnected water bodies of different trophic state, many years monitoring of which allowed to establish and reveal a number of fundamental patterns of functioning of aquatic ecosystems. Over the past 60 years, several stages in the evolution of the structure and functional organization of the ecosystem are clearly traced. Within the framework of the work the following periods were considered: 1) anthropogenic eutrophication (1978-1983); 2) oligotrophication (from 1984 to 1990 for Lake Naroch and from 1984 to 1990 for Lakes Myastro and Batorino) and 3) the period of bentification (since 1991 for Lake Naroch and since 1990 for Lakes Myastro and Batorino to the present). The values of the most part of parameters that are taken into account when assessing the trophic state of ecosystems (phosphorus, chlorophyll, phytoplankton, seston) are significantly reduced at bentification period compared to that of anthropogenic eutrophication. In the same time gross primary production of plankton in Lake Naroch actually did not change. One of the important reasons for this may be an increase in the depth of trophogenic layer and as a result an increase in its volume in regard to the entire volume of the lake. Production of submerged and emergent macrophytes in Lake Naroch during the period of bentification increased in 2 and 4 times respectively, compared with the period of eutrophication. The level of production of periphyton communities has not changed significantly. Based on the dynamics of the main hydroecological parameters of the Naroch lakes in different periods of their evolution, the uncertainty in assessing such a key characteristic of the ecosystem as its trophic state is evident, which can differ significantly depending on indicators that are used as the basis for its assessment in a specific waterbody.

Keywords: Naroch lakes, eutrophication, oligotrophication, bentification, trophic state.

Citation: Adamovich B.V., Zhukova T.V., Mikheyeva T.M., Kovalevskaya R.Z., Makarevich T.A., Zhukova H.A. Eutrophication, oligotrophication, and benthiphication in Naroch Lakes: 40 years of monitoring. J. Sib. Fed. Univ. Biol., 2017, 10(4), 379-394. DOI: $10.17516 / 1997-1389-0040$.

(C) Siberian Federal University. All rights reserved

* Corresponding author E-mail address: belaqualab@gmail.com 


\title{
Эвтрофирование, олиготрофикация
}

\section{и бентификация в Нарочанских озерах: \\ 40 лет мониторинговых исследований}

\author{
Б.В. Адамович, Т.В. Жукова, Т.М. Михеева, \\ Р.3. Ковалевская, Т.А. Макаревич, А.А. Жукова \\ Белорусский государственный университет \\ Республика Беларусь, 220030, Минск, пр. Независимости, 4
}

Нарочанские озера представляют собой систему из трех связанных между собой водоемов разной трофности, многолетний мониторинг которых позволил установить и раскрыть ряд фундаментальных закономерностей функиионирования водных экосистем. За последние 60 лет хорошо просматривается несколько этапов в эволюиии структурной и функииональной организачии экосистемы. В рамках работы рассмотрены периоды: 1) антропогенного эвтрофирования (1978-1983 гг.); 2) олиготрофикации (с 1984 по 1990 г. для оз. Нарочь, и с 1984 по 1989 г. для озер Мястро и Баторино) и 3) период бентификации (с 1991 г. для оз. Нарочь и с 1990 г. для оз. Мястро и Баторино по настоящее время). Практически все параметры, которые принято считать показательными при оченке трофности экосистемы (фосфор, хлорофилл, фитопланктон, сестон), существенно снизились в период бентификаџии по отнотению к периоду антропогенного эвтрофирования. При этом валовая первичная продукиия планктона в оз. Нарочь фактически не изменилась. Одной из важных причин этого может быть возрастание трофогенного слоя $и$, соответственно, увеличение соотночения его объема ко всему объему озера. Продукиия погруженных и воздушно-водных макрофитов в оз. Нарочь в период бентификации увеличилась в 2 и 4 раза соответственно в сравнении с периодом эвтрофирования. Уровень продукиии перифитонных сообществ существенно не изменился. На примере динамики основных гидроэкологических показателей Нарочанских озер в разные периоды их эволюиии очевидна неоднозначность в оценке такой ключевой характеристики экосистемы, как ее трофический статус, который может существенно отличаться в зависимости от того, какие показатели положены в основу его оценки в конкретном водном объекте.

Ключевые слова: Нарочанские озера, эвтрофирование, олиготрофикация, бентификация, трофический статус.

\section{Введение}

Система Нарочанских озер - уникальный объект из трех связанных между собой водоемов разной трофности, многолетний мониторинг которых позволил установить и раскрыть ряд фундаментальных закономер- ностей функционирования водных экосистем. В 1946 г. на озере была основана Нарочанская биологическая станция Белорусского государственного университета и начаты системные гидроэкологические исследования. Круглогодичный мониторинг озер Нарочь, 
Мястро и Баторино ведется по единой программе с 1978 г.

Мониторинговые наблюдения Нарочанских озер дали возможность выявить, что за последние 60 лет хорошо просматривается несколько этапов в эволюции структурной и функциональной организации экосистемы. Выделен ряд внешних факторов, в значительной мере определивших этапы эволюции экосистемы Нарочанских озёр и её современное состояние (Остапеня и др., 2012). Активное сельскохозяйственное производство и, как следствие, усиление биогенной нагрузки на водосбор привели к прогрессирующему эвтрофированию водоёмов в середине 1970-х гг. В дальнейшем существенное влияние на экосистему Нарочанских озер оказали два внешних фактора: 1) реализация с 1981 г. Государственной программы комплексного использования и охраны водных и земельных ресурсов бассейна оз. Нарочь, в результате выполнения которой внешняя биогенная нагрузка на экосистему, по оценкам экспертов (Жукова, Остапеня, 2000), снизилась к середине 1980 -х гг. на $30 \%$, что, по сути, стало началом периода олиготрофикации; 2) вселение и массовое распространение с начала 1990-х гг. во всех трех озерах моллюскафильтратора Dreissena polymorpha Pallas.

Этап эволюции экосистемы Нарочанских озер с 1990-х гг. можно описать термином «бентификация». Термин был впервые использован для характеристики влияния моллюска D. polymorpha на экосистемы и продукционные процессы оз. Онтарио (Mills et al., 2003), а именно трансформацию местообитания («еcosystem engineering»), увеличение прозрачности воды и сдвиг продукционных процессов в сторону донных сообществ (Zhu et al., 2006). В русскоязычной литературе этот термин впервые употребил А.П. Остапеня (Остапеня, 2007), описав основные механиз- мы бентификации на примере экосистемы Нарочанских озер (Остапеня и др., 2012) - сдвиг продукционных потоков от планктонных сообществ к бентосным и перифитонным при сохранении продукционного уровня экосистемы в целом. Вклад различных сообществ в первичную продукцию экосистемы рассмотрен в основополагающей работе о процессах бентификации в Нарочанских озерах А.П. Остапени с соавторами (Остапеня и др., 2012).

В настоящей работе основное внимание сконцентрировано на сравнении в периоды эвтрофирования и бентификации гидроэкологических показателей, традиционно принятых для классификации водоемов по трофическому статусу. Такие показатели условно можно разделить на две группы: к первой относятся «статичные» параметры, такие как прозрачность воды, содержание в воде сестона, химических элементов и соединений, а также биомасса водных сообществ; ко второй - продукционные характеристики водных (в основном автотрофных) компонентов экосистемы. В отличие от предыдущих работ выделенные периоды эвтрофирования, олиготрофикации и бентификации одинаковы для всех рассмотренных гидроэкологических параметров.

\section{Материал и методы}

Озера Баторино, Мястро и Нарочь расположены на северо-западе Беларуси, принадлежат бассейну p. Неман и представляют собой систему из трех водоемов, имеющих общую водосборную территорию и соединенных между собой протоками (рис. 1).

Озера являются полимиктическими (относительно большая площадь и небольшая средняя глубина способствуют интенсивному динамическому перемешиванию водной массы в течение безледного периода), но раз- 


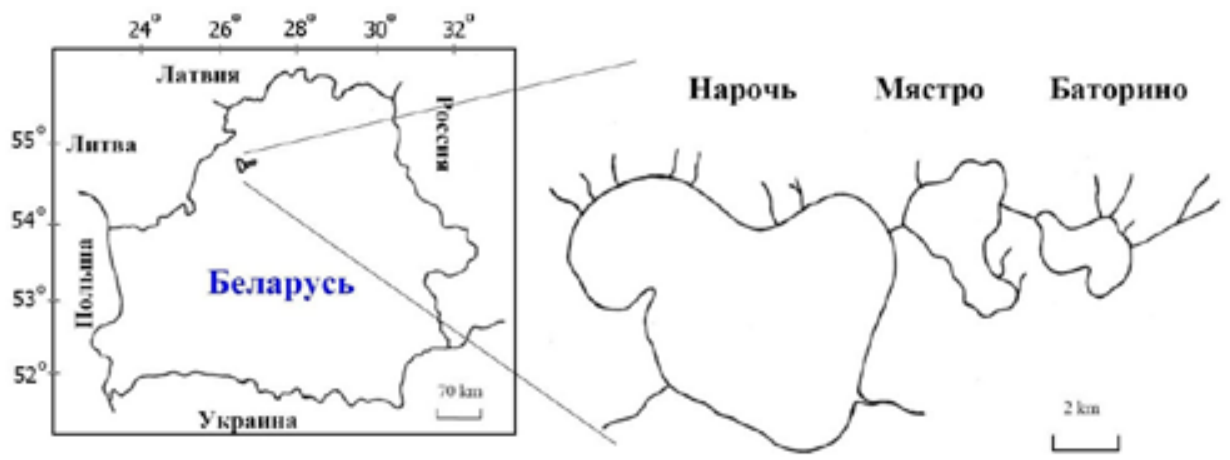

Рис. 1. Расположение экосистемы Нарочанских озер

Fig. 1. Location of the ecosystem of Naroch lakes

Таблица 1. Основные характеристики Нарочанских озер

Table 1. Main characteristics of the Naroch lakes

\begin{tabular}{|l|c|c|c|}
\hline \multicolumn{1}{|c|}{ Показатели } & оз. Баторино & оз. Мястро & оз. Нарочь \\
\hline Площадь водного зеркала, км & & 79,6 \\
Объем водной массы, млн м & 6,3 & 73,1 & 710,0 \\
Глубина, м (средняя/максимальная) & 18,7 & 70,1 & $8,9 / 24,8$ \\
Время водообмена, лет & $2,4 / 5,5$ & $5,4 / 11,3$ & $10-11$ \\
\hline
\end{tabular}

личаются по морфометрическим и гидрологическим характеристикам (табл. 1).

Мониторинговые исследования проводили в глубоководной зоне озер на станциях и горизонтах постоянных наблюдений 1-3 раза в месяц во время вегетационного сезона. В зависимости от погодных условий первый отбор осуществляли в апреле или мае, последний - в ноябре. Пробы воды отбирали при помощи 2-литрового батометра Рутнера на шести горизонтах водного столба $(0,5 ; 3 ; 6 ; 8$;

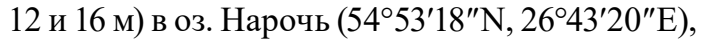
четырех горизонтах $(0,5 ; 4 ; 7$ и 9 м) в оз. Мя-

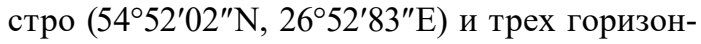
тах $\left(0,5 ; 3\right.$ и 5 м) в оз. Баторино $\left(54^{\circ} 50^{\prime} 80^{\prime \prime} \mathrm{N}\right.$, $\left.26^{\circ} 80^{\prime} 06^{\prime \prime} \mathrm{E}\right)$. При мониторинговых наблюдениях воду со всех горизонтов смешивали для получения интегральной пробы, отражающей средний состав озерной воды (объем воды каждого горизонта в интегральной пробе был пропорционален доле, которую составляет данный слой в общем объеме озера в соответствии с данными батиметрии). Прозрачность воды (SD) определяли по стандартному белому диску Секки. Содержание взвешенных веществ (Seston) определяли гравиметрическим методом на мембранных фильтрах с диаметром пор 1,5 мкм. На этих же фильтрах оценивали содержание хлорофилла $a$ без коррекции на присутствие феопигментов (Chl.a) спектрофотометрическим методом с экстракцией пигментов в 90\%-м ацетоне (SCOR-UNESCO, 1966). Общее содержание азота (TN) определялось после минерализации нефильтрованной воды по методу Кьельдаля или окисления проб с персульфатом калия в автоклаве, фосфора (ТР) - после минерализации нефильтрованной воды с персульфатом калия в кислой 
среде на водяной бане (Унифицированные методы ..., 1973; Руководство по химическому анализу ..., 1977; Методы исследования органического ..., 1980).

Фиксацию проб фитопланктона (объемом 0,5 л) проводили по Утермелю в модификации Т.М. Михеевой (Михеева, 1989). Концентрировали пробы осадочным методом. Плотность (N) и биомассу (B) фитопланктона определяли стандартным счетно-объемным методом. Учет водорослей проводили в камеpe Фукс-Розенталя. Индивидуальную массу клеток определяли методом геометрического подобия. Формы геометрических тел, к которым приравниваются клетки водорослей, и формулы для расчета их объемов приведены в работах Т.М. Михеевой (1999) и Hillebrand et al. (1999).

Для определения первичной продукции и деструкции планктона применяли скляночный метод в кислородной модификации (Винберг, 1960). В оз. Нарочь измерения проводили в глубоководной зоне на протяжении вегетационного сезона (май-октябрь) в середине каждого месяца. Светлые и затемненные склянки объемом 150 мл (по две параллельных) заполняли водой с каждого горизонта. Склянки устанавливали на семи горизонтах на глубинах 0,$5 ; 2 ; 4 ; 6 ; 9 ; 12$ и 15 м. Интегральную продукцию и деструкцию рассчитывали как площадь под кривой методом трапеций. Также методом трапеций рассчитывали суммарные продукцию и деструкцию за вегетационный сезон.

Описание зарастания Нарочанских озер макрофитами проводили методом профилирования (Катанская, 1981; Экологическая система ..., 1985). В 2004 г. оконтуривание воздушно-водных макрофитов шло с помощью GPS; в 2016 г. - по аэрофотоснимкам. При расчете продукции всех растительных сообществ кроме харовых водорослей исполь- зовали Р/В коэффициент 1,2 (Распопов, 1973; Экологическая система ..., 1985), для харовых водорослей был взят $\mathrm{P} / \mathrm{B}=0,75$. Использовали следующие величины содержания органического вещества в макрофитах (в \% от абсолютно сухой массы): воздушно-водная растительность - 83, погруженная (кроме харовых водорослей) - 67, харовые водоросли - 30 \% (Экологическая система ..., 1985).

В работе использованы следующие пересчетные коэффициенты: 1 мг $\mathrm{O}_{2}-3,38$ кал, 1 мг С - 2,15 мг органического вещества, 1 мг $\mathrm{O}_{2}-0,3$ мг С.

Индекс трофического состояния Карлсона (TSI) рассчитывали по трем параметрам (Carlson, 1977) - прозрачность по диску Секки, концентрация хлорофилла $a$ и общего фосфора - по формулам (Adamovich et al., 2016), описывающим логарифмические кривые изменения индекса. В качестве интегрированного значения взято среднее из трех рассчитанных индексов (Adamovich et al., 2016).

Статистическую обработку и визуализацию данных проводили с использованием программного пакета R.

\section{Результаты}

Анализ внешних факторов, а также многолетней динамики основных гидроэкологических параметров позволил выделить несколько периодов эволюции экосистемы Нарочанских озер. В рамках данной работы мы рассмотрели следующие периоды: 1) антропогенного эвтрофирования (1978-1983 гг.); 2) олиготрофикации (с 1984 по 1990 г. для оз. Нарочь и с 1984 по 1989 г. для озер Мястро и Баторино); 3) период бентификации (с 1991 г. для оз. Нарочь и с 1990 г. для озер Мястро и Баторино по настоящее время). Разные сроки начала периода бентификации в озерах приняты нами в связи с тем, что, исходя из имеющихся данных, существенное воздей- 
ствие дрейссены на экосистему в озерах Мястро и Баторино началось несколько раньше, чем в оз. Нарочь. Так, в оз. Мястро дрейссена впервые была отмечена в 1984 г. (Остапеня и др., 1994; Бурлакова, 1998). Примерно этим же временем датируются первые находки дрейссены в оз. Баторино (Остапеня и др., 1994а). В оз. Нарочь первые особи дрейссены были зарегистрированы в 1989 г. (Остапеня и др., 1993), и в следующие годы отмечен скачкообразный рост популяции дрейссены. Так, если в 1990 г. средняя биомасса дрейссены ( \pm стандартная ошибка) в оз. Нарочь составляла $(1,5 \pm 0,6) \Gamma / \mathrm{M}^{2}$, то уже в 1993 г. $(99 \pm 30)$ г/м², и такие значения биомассы сохранялись практически на неизменном уровне до 1997 г. В оз. Мястро средняя биомасса

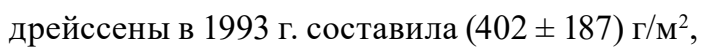
а в оз. Баторино - $(79 \pm 13)$ г/м². В 1995 г. отмечено некоторое снижение биомассы моллюска в оз. Мястро $\left(288 \pm 118 \Gamma / \mathrm{M}^{2}\right)$ и ее увеличение в оз. Баторино $\left(100 \pm 36 \Gamma / \mathrm{M}^{2}\right)$ (Burlakova et al., 2006). Учитывая, что в большинстве отмеченных случаев (Burlakova et al., 2006) уже в течение 2 лет после первого обнаружения в озере дрейссена достигает близких к максимуму величин, можно предположить, что с 1991 г. в оз. Нарочь и немного раньше в озеpax Мястро и Баторино дрейссена начинает существенно влиять на экосистемные процессы. Подтверждением этому также может служить анализ моделей АРПСС для динамики сестона Нарочанских озер (Zhukova et al., 2017). По результатам анализа временных рядов сестона можно сделать вывод, что для всех озер Нарочанской группы помимо закономерных сезонных флуктуаций имело место относительно резкое воздействие (интервенция), приведшее к быстрому уменьшению концентрации сестона и снижению колебаний его величин. При этом для озер Баторино и Мястро основной отклик экосистемы на это воздействие приходится на 1990 г., а для оз. Нарочь - на 1991 г.

В оз. Нарочь в период бентификации прозрачность воды увеличилась в среднем на 1,5 м по сравнению с периодом эвтрофирования (рис. 2). При этом содержание в воде общего фосфора снизилось с 34,3 до 14,5 мкг/л, хлорофилла $a-\mathrm{c} 4,7$ до 1,4 мкг/л, взвешенного вещества - с 1,8 до 0,9 мг/л, а биомасса фитопланктона - с 1,43 до 1,09 мг/л. Интересно, что средние значения содержания хлорофилла $a$, сестона и биомасса фитопланктона для периодов эвтрофирования и олиготрофикации были практически одинаковыми, в то время как концентрация общего фосфора в период олиготрофикации резко снизилась. В оз. Мястро, по сравнению с периодом эвтрофирования, в период бентификации прозрачность воды увеличилась с 1,6 до 4 м (рис. 3). Содержание в воде общего фосфора снизилось с 58,9 до 34,3 мкг/л, хлорофилла $a-$ с 24,4 до 4,5 мкг/л, взвешенного вещества - с 6,4 до 2,2 мг/л, биомасса фитопланктона - с 6,79 до 2,72 мг/л. В оз. Баторино в период бентификации прозрачность воды увеличилась с 0,8 до 1,2 м (рис. 4). Содержание в воде общего фосфора снизилось с 90,0 до 36,5 мкг /л, хлорофилла $a-$ с 58,0 до 9,3 мкг/л, взвешенного вещества - с 16,8 до 7,8 мг/л и биомассы фитопланктона - с 19,53 до 9,51 мг/л. Как и в случае с оз. Нарочь, снижение всех показателей в период олиготрофикации в озерах Мястро и Баторино было менее существенным, чем в период бентификации.

По всем рассмотренным параметрам период бентификации четко отличается от периода антропогенного эвтрофирования, при этом показатели во всех трех озерах относительно стабильны уже довольно продолжительное время (рис. 2-4).

Наиболее полные сведения о величинах первичной продукции различных компонен- 
A

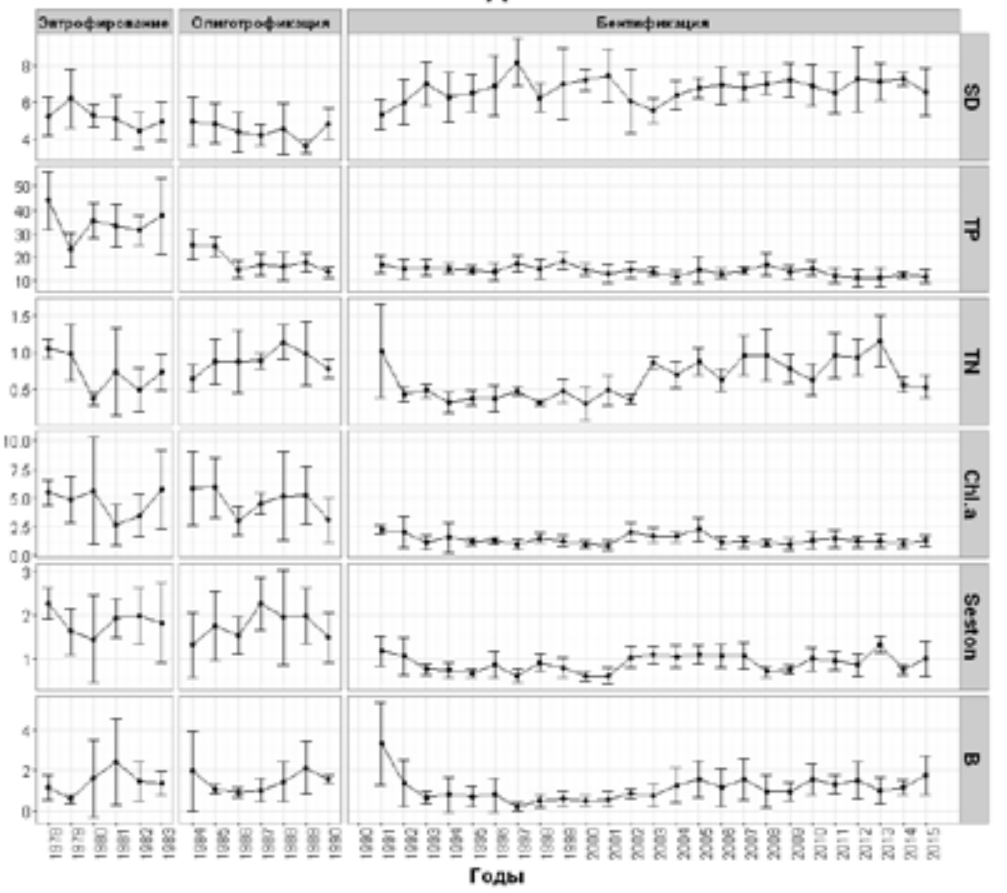

5

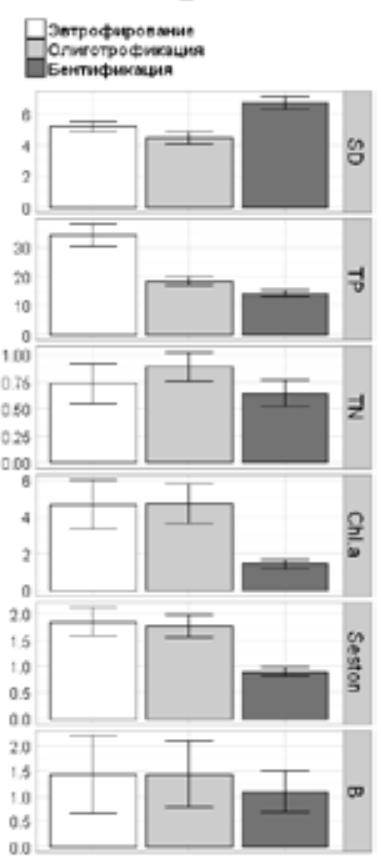

Рис. 2. Основные гидроэкологические показатели оз. Нарочь в разные периоды наблюдений: А - средние значения за вегетационный сезон (май-октябрь) и стандартные отклонения; Б - средние для периодов исследований и стандартные отклонения для среднесезонных значений. Обозначения: SD - прозрачность по диску Секки (м), TP - общий фосфор (мкг/л), TN - общий азот (мг/л), Chl.a - хлорофилл $a$ (мкг/л), Seston - сестон (мг сух. вещества/л), В - биомасса фитопланктона (мг/л)

Fig. 2. The main hydroecological indicators of the Lake Naroch in different periods of observations: A - mean values for the growing season (May-October) and standard deviations; B - means for the periods of studies and standard deviations for the average seasonal values. Legend: SD - Secchi depth (m), TP - total phosphorus $(\mu \mathrm{g} / \mathrm{l}), \mathrm{TN}$ - total nitrogen $(\mathrm{mg} / \mathrm{l}), \mathrm{Chl} . \mathrm{a}$ - chlorophyll a ( $\mu \mathrm{g} / \mathrm{l})$, Seston - seston (mg. dry matter/l), B - biomass of phytoplankton (mg/l)

тов экосистемы в периоды эвтрофирования и бентификации имеются для оз. Нарочь. Так, среднее значение первичной продукции планктона в 2004-2016 гг. в пелагической части оз. Нарочь на пункте постоянных наблюдений (глубина 16 м) для шести месяцев вегетационного сезона составило 0,45 гC/( $\mathrm{M}^{2} \cdot$ сут), де-

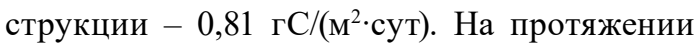
вегетационного сезона, как и в среднем для всего указанного периода, деструкция превышала первичную продукцию (табл. 2), что может свидетельствовать о важной роли процессов трансформации вещества, проходящих через гетеротрофный бактериопланктон и по- лучивших название «микробиальной петли» (Pomeroy, 1974), а также деструкции в профундали органического вещества, созданного непланктонными первичными продуцентами (макрофитами, фитоперифитоном и т.п.).

Валовая первичная продукция планктона в оз. Нарочь за вегетационный сезон (майоктябрь) в 2004-2016 гг. составила в среднем ( \pm стандартное отклонение) $(84,6 \pm 13,5)$ гС/ $\mathbf{M}^{2}$ (или 953,3 $\pm 147,2$ ккал/ $\mathbf{M}^{2}$ ), что очень близко к аналогичным величинам продукции планктона, отмеченным в 1976-1977 гг. в период антропогенного эвтрофирования. Так, валовая первичная продукция планктона за 
A

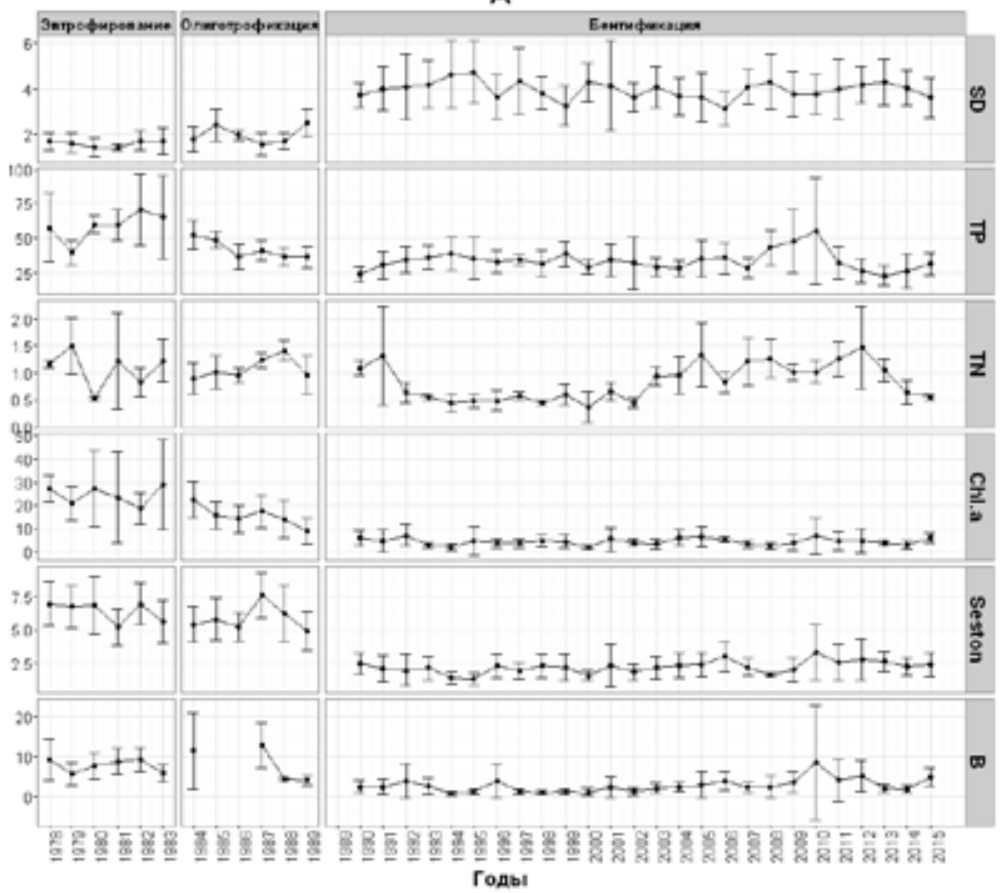

E

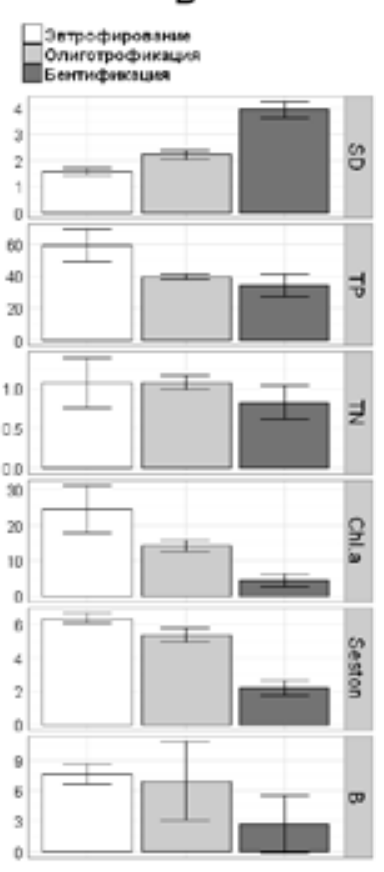

Рис. 3. Основные гидроэкологические показатели оз. Мястро в разные периоды наблюдений: А - средние значения за вегетационный сезон (май-октябрь) и стандартные отклонения; Б - средние для периодов исследований и стандартные отклонения для среднесезонных значений. Обозначения: см. рис. 2

Fig. 3. The main hydroecological indicators of Lake Myastro in different periods of observation: A - mean values for the growing season (May-October) and standard deviations; B - means for the periods of studies and standard deviations for the average seasonal values. Legend: see Fig. 2

Таблица 2. Продукционно-деструкционные показатели планктона (гС/(м²·cут)) на пункте постоянных наблюдений (глубина 16 м) в оз. Нарочь в 2004-2016 гг. (приведены средние значения \pm стандартное отклонение, $\mathrm{n}$ - количество наблюдений)

Table 2. Production and destruction parameters of plankton $\left(\mathrm{gC} /\left(\mathrm{m}^{2} \cdot\right.\right.$ day $\left.)\right)$ at the station of continuous observations (depth $16 \mathrm{~m}$ ) in the Lake Naroch in 2004-2016 (mean values \pm standard deviation, $\mathrm{n}$ - number of observations)

\begin{tabular}{|c|c|c|c|c|}
\hline Месяц & $\begin{array}{c}\text { Валовая первичная } \\
\text { продукция }\end{array}$ & Деструкция & $\begin{array}{c}\text { Чистая первичная } \\
\text { продукция }\end{array}$ & $\mathrm{n}$ \\
\hline Май & $0,44 \pm 0,16$ & $0,65 \pm 0,26$ & $-0,21 \pm 0,21$ & 13 \\
Июнь & $0,48 \pm 0,18$ & $0,72 \pm 0,40$ & $-0,25 \pm 0,30$ & 13 \\
Июль & $0,57 \pm 0,15$ & $1,10 \pm 0,46$ & $-0,53 \pm 0,38$ & 13 \\
Август & $0,53 \pm 0,28$ & $1,18 \pm 0,43$ & $-0,65 \pm 0,55$ & 11 \\
Сентябрь & $0,46 \pm 0,14$ & $0,77 \pm 0,39$ & $-0,38 \pm 0,22$ & 12 \\
Октябрь & $0,22 \pm 0,10$ & $0,42 \pm 0,23$ & $-0,22 \pm 0,17$ & 85 \\
Среднее & $0,45 \pm 0,07$ & $0,81 \pm 0,23$ & $-0,37 \pm 0,18$ & \\
\hline
\end{tabular}



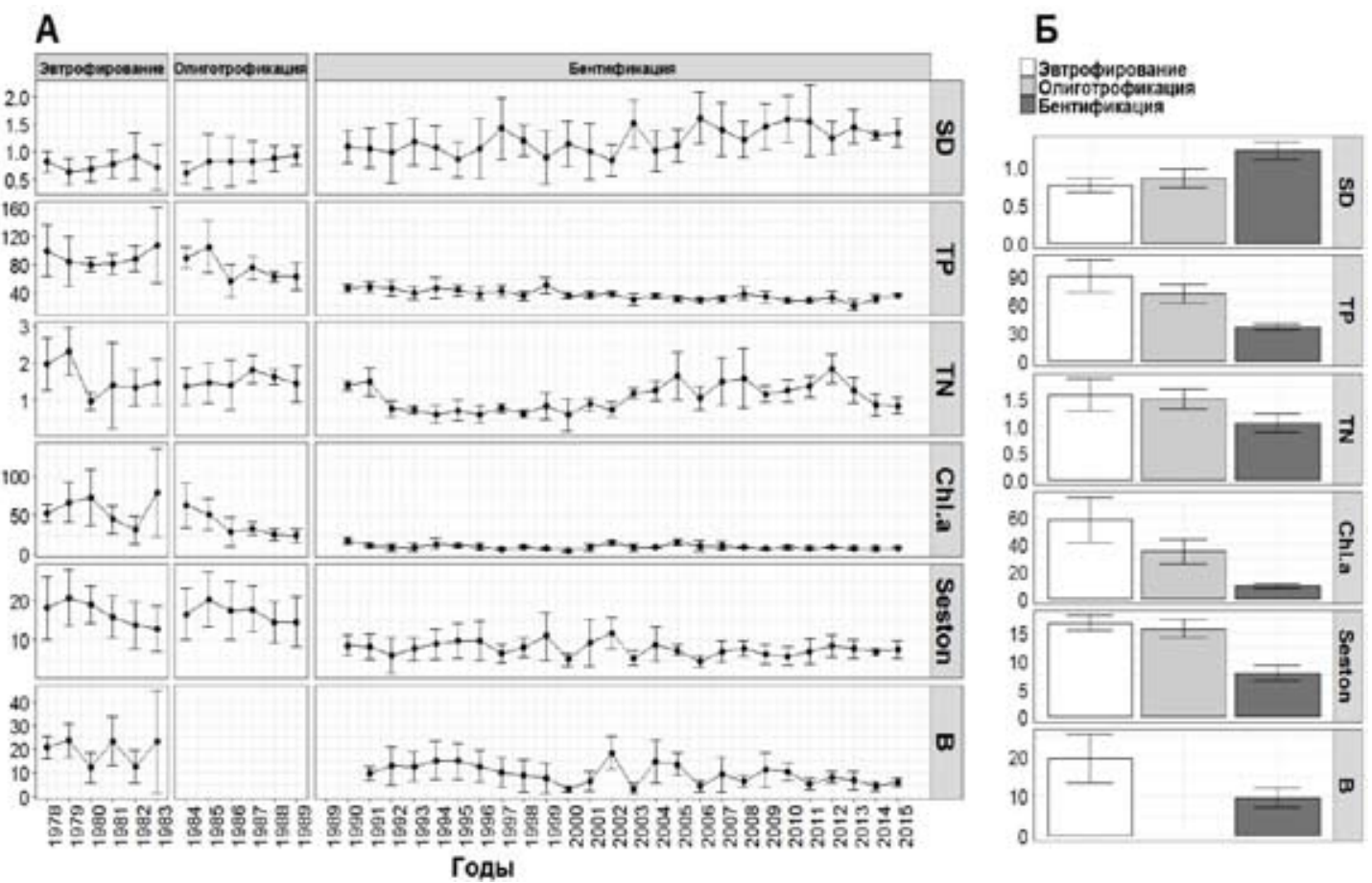

Рис. 4. Основные гидроэкологические показатели оз. Баторино в разные периоды наблюдений: А - средние значения за вегетационный сезон (май-октябрь) и стандартные отклонения; Б - средние для периодов исследований и стандартные отклонения для среднесезонных значений. Обозначения: см. рис. 2

Fig. 4. The main hydroecological indicators of the Lake Batorino in different periods of observations: A - mean values for the growing season (May-October) and standard deviations; B - means for the periods of studies and standard deviations for the average seasonal values. Legend: see Fig. 2

май-октябрь в 1976 г. составила 969 ккал/м² , в 1977 г. - 915 ккал/м² (Экологическая система..., 1985). В 2004-2016 гг. несколько увеличилась деструкция, составив $(286,0 \pm 44,2)$ гС/ м $^{2}$ (или $1816,5 \pm 432,9$ ккал/м²), против 1229,6 и 863 ккал/м² соответственно в 1976 и 1977 гг. Из табл. 3 видно, что средние значения валовой первичной продукции планктона на протяжении вегетационного сезона практически идентичны для периодов эвтрофирования и бентификации. В мае и октябре средние значения продукции были немного выше в период до 1983 г., в остальные месяцы - в 20042016 гг.

Если первичная продукция планктона в оз. Нарочь практически не изменилась, то биомасса и продукция макрофитов увели- чилась, как и площадь зарастания озера. По данным 1978-1981 гг., площадь зарастания воздушно-водными макрофитами не превышала 3 \% площади озера $(2,39$ км²) (Экологическая система..., 1985). К 2004 г. она увеличилась до 2,73 км², а по данным 2016 г. составила 3,43 км$^{2}$ (или 4,3\% акватории озера). При этом общая биомасса воздушно-водных макрофитов в период максимального развития (конец июля) увеличилась в 3,9 раза с 1978-1981 гг. к 2004-2016 гг., причем, как видно из табл. 4, в 2004 и 2016 гг. были отмечены схожие величины биомассы, что свидетельствует об относительной стабильности сообщества воздушноводных макрофитов в период бентификации. Биомасса воздушно-водных макрофитов в оз. Нарочь увеличилась с 1978-1981 гг. более 
Таблица 3. Валовая первичная продукция (ВПП) планктона (гС/(м².сут)) на пункте постоянных наблюдений (глубина 16 м) в оз. Нарочь в период эвтрофирования (среднее \pm стандартное отклонение, $\mathrm{n}$ - количество наблюдений) и отношение продукции в период бентификации (2004-2016 гг.) к периоду эвтрофирования (1968-1983 гг.)

Table 3. Gross primary production (GPP) of plankton $\left(\mathrm{gC} /\left(\mathrm{m}^{2} \cdot\right.\right.$ day)) at the station of continuous observations (depth $16 \mathrm{~m}$ ) in the Lake Naroch during the eutrophication period (mean \pm standard deviation, $\mathrm{n}-$ number of observations) and the ratio of production during the period of benification (2004-2016) to the eutrophication period (1968-1983)

\begin{tabular}{|c|c|c|c|}
\hline Месяц & $\begin{array}{c}\text { ВПП, } \\
1968-1983 \text { гг. }\end{array}$ & $\mathrm{n}$ & $\begin{array}{c}\text { Отношение ВПП в период бентификации } \\
\text { к периоду эвтрофирования }\end{array}$ \\
\hline Май & $0,56 \pm 0,14$ & 6 & 0,8 \\
Июнь & $0,40 \pm 0,08$ & 8 & 1,2 \\
Июль & $0,50 \pm 0,14$ & 5 & 1,1 \\
Август & $0,50 \pm 0,18$ & 9 & 1,1 \\
Сентябрь & $0,37 \pm 0,14$ & 4 & 1,2 \\
Октябрь & $0,27 \pm 0,12$ & 5 & 0,8 \\
Среднее & $0,43 \pm 0,04$ & & 1,0 \\
\hline
\end{tabular}

Таблица 4. Биомасса (В) и продукция (Р) макрофитов в оз. Нарочь (данные 1978-1981 гг.-по (Экологическая система ..., 1985); н/о - не определяли)

Table 4. Biomass (B) and production (P) of macrophytes in the Lake Naroch (data of 1978-1981 - from (Ecological system ..., 1985); H/o - did not determine)

\begin{tabular}{|c|c|c|c|c|}
\hline \multirow{2}{*}{ Год } & \multicolumn{2}{|c|}{ В, т абсолютно сухой массы } & \multicolumn{2}{|c|}{ Р, т С } \\
\cline { 2 - 5 } & воздушно-водных & погруженных & воздушно-водных & погруженных \\
\hline 1978 & 230 & 3431 & 107 & 544 \\
1979 & 927 & 5573 & 429 & 883 \\
1980 & 891 & 3577 & 413 & 567 \\
1981 & 782 & 3896 & 362 & 617 \\
1999 & H/o & 8362 & H/o & 1325 \\
2004 & 2838 & H/o & 1314 & H/o \\
2016 & 2680 & H/o & 1241 & н/o \\
\hline
\end{tabular}

чем в 2 раза (табл. 4), соответственно возросла и их продукция.

Валовая первичная продукция перифитона по данным для периода 1980-1985 гг. за

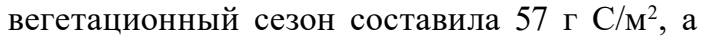
для периода 2004-2009 гг. - 47 г С/м² (Остапеня и др., 2012). Кроме того, за счет раковин дрейссены в период бентификации появилась значительная дополнительная поверхность твердого субстрата для развития перифитона.
Суммарная поверхность раковин дрейссены в оз. Нарочь оценена в 8,36 км² (Mastitsky, Makarevich, 2007). К середине вегетационного сезона на этой поверхности формируется около 104 т органического вещества перифитона. Величина валовой первичной продукции перифитона на раковинах дрейссены составляет около 2,5 т органического вещества за сутки, что примерно соответствует 2 \% общей валовой первичной продукции, создаваемой в 
озере планктоном, макрофитами и развивающимся на них перифитоном, и микрофитобентосом (Макаревич и др., 2011). С учетом этого величины продукции перифитона в периоды эвтрофирования и бентификации будут еще более близкими.

\section{Обсуждение}

В оз. Нарочь, по сравнению с периодом эвтрофирования, в период бентификации прозрачность воды увеличилась на 30 \%, содержание в воде общего фосфора снизилось более чем в 2 раза, хлорофилла $a$ - более чем в 3 раза, взвешенного вещества - в два раза, а биомассы фитопланктона - в 1,3 раза. Близкие значения содержания хлорофилла $a$, сестона и биомассы фитопланктона для периодов эвтрофирования и олиготрофикации, при значительном снижении концентрации общего фосфора в воде, показывают направленность влияния бентификации на основные гидроэкологические параметры Нарочанских озер. В оз. Мястро в период бентификации прозрачность воды увеличилась в среднем в 2,5 раза, содержание в воде общего фосфора снизилось в 1,7 раза, взвешенного вещества и биомассы фитопланктона - практически в 3 раза, хлорофилла $a$-более чем в 5 раз. В оз. Баторино прозрачность воды увеличилась в 1,6 раза, содержание в воде общего фосфора снизилось в 2,5 раза, взвешенного вещества и биомассы фитопланктона - более чем вдвое, хлорофилла $a$ - более чем в 6 раз. Как и в оз. Нарочь, снижение всех показателей в период олиготрофикации в озерах Мястро и Баторино были менее существенными, чем в период бентификации.

Таким образом, практически все основные показатели трофического статуса в толще воды Нарочаскних озер снизились в период бентификации в несколько раз по отношению к периоду антропогенного эвтрофирования в конце 1970-х - начале 1980-х гг.

Если оценивать трофический статус озер на основании популярного в современной лимнологии индекса Карлсона (TSI - trophy state index), видно, что с начала первой половины 1980-х гг. отмечен период устойчивого снижения индекса во всех трех озерах Нарочанской группы (рис. 5). По индексу Карлсона трофические условия в озерах в различные периоды изменялись от высокоэвтрофных (оз.

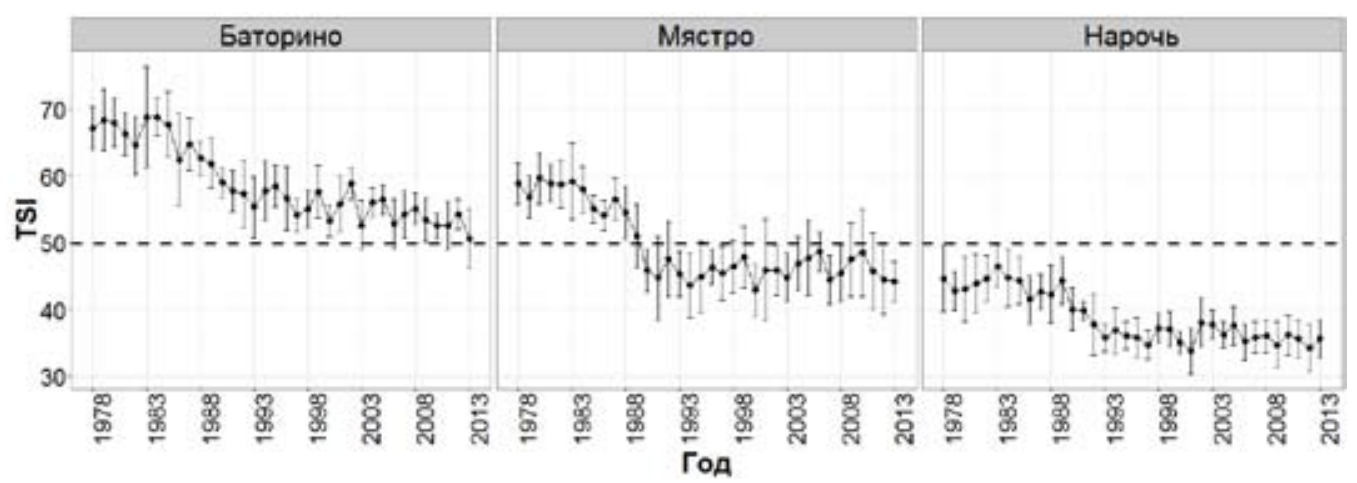

Рис. 5. Многолетние изменения индекса трофического состояния Карлсона (TSI) и стандартные отклонения для его значений в Нарочанских озерах (пунктирная линия обозначает условную границу эвтрофной и мезотрофной зон) (По: Adamovich et al., 2016)

Fig. 5. Long-term changes in the Carlson trophy state index (TSI) and standard deviations for its values in the Naroch lakes (the dotted line denotes the nominal boundary of the eutrophic and mesotrophic zones) (From: Adamovich et al., 2016) 
Баторино) до олиготрофных (оз. Нарочь). С конца 1970-х гг. к 2013 г. средние для вегетационного сезона значения TSI верхнего в системе озер - оз. Баторино, опустились с границы высокоэвтрофной зоны (70) к условной границе эвтрофной и мезотрофной зон (50). В оз. Мястро среднесезонный TSI сдвинулся ниже границы эвтрофной и мезотрофной зон в конце 1980-х гг. В оз. Нарочь TSI практически на протяжении всего рассматриваемого периода находился в области мезотрофных значений, в отдельные месяцы последних лет опускаясь ниже 30 , в олиготрофную область (Adamovich et al., 2016). В среднем TSI снизился от периода эвтрофирования к периоду бентификации с 44,3 до 36,1 в оз. Нарочь, с 58,8 до 45,9 в оз. Мястро и с 67,2 до 55,1 в оз. Баторино.

При этом первичная продукция планктона в оз. Нарочь фактически не изменилась в период бентификации по сравнению с периодом эвтрофирования в отличие от статичных параметров, которые принято считать показательными при оценке трофности экосистемы (фосфор, хлорофилл, фитопланктон, сестон, прозрачность). Одной из основных причин этого может быть увеличение трофогенного слоя и, соответственно, увеличение отношения его объема ко всему объему озера (рис. 6). Это создает предпосылки для эффективной фотосинтетической активности планктона в гораздо большем объеме воды, чем наблюдалось в периоды антропогенного эвтрофирования и олиготрофикации.

Кроме того, фотосинтетическая активность хлорофилла « $a$ », оцененная по величине суточного ассимиляционного числа (САЧ) на глубине максимального фотосинтеза $\left(\mathrm{A}_{\max }\right)$, по сравнению с концом 70-х - началом 80-х гг. прошлого века в каждом из озер увеличились в период бентификации более чем в два раза (Михеева и др., 2006).

На основании данных за 2004-2016 гг. первичная продукция планктона за вегетационный сезон на протяжении длительного периода бентификации изменялась в достаточно узких для естественных водоемов пределах, т.е. экосистема озера в этот период оставалась относительно стабильна по своим продукционным характеристикам.

Значения удельной первичной продукции перифитона в оз. Нарочь в период бентификации несколько снизились в сравнении с предыдущим периодом, однако с учетом
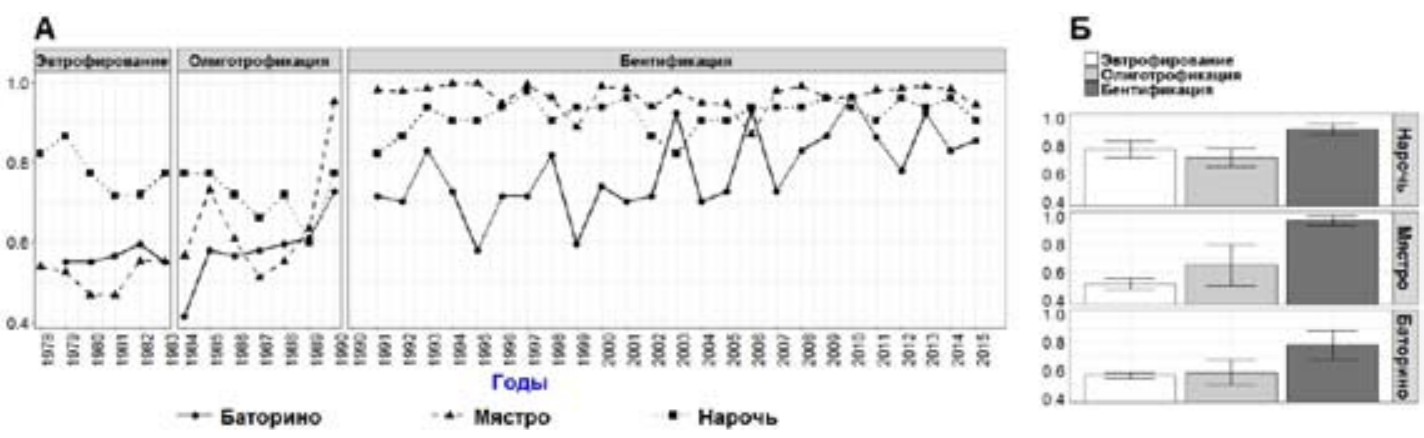

Рис. 6. Отношения объема трофогенного слоя (две прозрачности по диску Секки) к общему объему озера: А - многолетняя динамика, Б - средние и стандартные отклонения для периодов исследований (По: Остапеня, 2014, с дополнениями)

Fig. 6. The ratio of the volume of the trophogenic layer (estimated as $2 \mathrm{x}$ Secchi depth) to the total volume of the lake: A - the long-term dynamics, B - the mean and standard deviations for the periods of research (modified from: Ostapenya, 2014, with additions) 
сложности в оценке первичной продукции этого компонента экосистемы, а также дополнительной продукции на поверхности раковин дрейссены можно считать, что суммарный уровень продукции перифитона также сохраняется довольно близким. В то же время продукция погруженных и воздушно-водных макрофитов в оз. Нарочь в период бентификации увеличилась в 2 и 4 раза соответственно.

\section{Заключение}

Таким образом, сравнение основных гидроэкологических параметров в периоды эвтрофирования и бентификации показало, что практически все основные показатели трофического статуса в толще воды Нарочанских озер, такие как прозрачность, содержание общего фосфора, хлорофилла, сестона, биомасса фитопланктона, снизились в период бентификации в несколько раз по отношению к периоду антропогенного эвтрофирования. Существенно снизился индекс трофического состоянии (TSI) озер. При этом валовая первичная продукция планктона в оз. Нарочь фактически не изменилась. Продукция погруженных и воздушно-водных макрофитов в оз. Нарочь в период бентификации увеличилась в 2 и 4 раза соответственно в сравнении с периодом эвтрофирования. На примере динамики основных гидроэкологических показателей Нарочанских озер в разные периоды их эволюции очевидна неоднозначность в оценке такого ключевого параметра экосистемы, как ее трофический статус, который может очень отличаться в зависимости от того, какие показатели положены в основу его оценки в конкретном водном объекте. Приобретает также актуальность вопрос адекватной оценки трофического статуса без учета данных о первичной продукции как планктона, так и экосистемы в целом при том, что в подавляющем большинстве современных работ трофический статус оценивается исходя из гидрохимических показателей и/или статичных показателей планктонных сообществ (численности, биомассы), что, как показывают многолетние исследования Нарочанских озер, может давать противоречивые результаты.

\section{Список литературы}

Бурлакова Л.Е. (1998) Экология Dreissena polymorpha (Pallas) и ее роль в структуре и функиионировании водных экосистем: Автореф. дис. ... канд. биол. наук. Минск, Институт зоологии НАН Беларуси, 18 с. [Burlakova L.E. (1998) Ecology of Dreissena polymorpha (Pallas) and its role in the structure and functioning of aquatic ecosystems: Abstract of the Dis. ... Cand. Biol. Sciences. Minsk, Institute of Zoology of the National Academy of Sciences of Belarus, 18 p. (in Russian)]

Винберг Г.Г. (1960) Первичная продукция водоемов. Минск, Изд-во АН БССР, 330 с. [Vinberg G.G. (1960) Primary production of water bodies. Minsk, Academy of Sciences of the BSSR, 330 p. (in Russian)]

Жукова Т.В., Остапеня А.П. (2000) Оценка эффективности природоохранных мероприятий на водосборе Нарочанских озер. Природныле ресурсы, 3: 68-73 [Zhukova T.V., Ostapenya A.P. (2000) Evaluation of the effectiveness of environmental measures in the catchment area of the Naroch Lakes. Natural Resources [Prirodnye resursy], 3: 68-73 (in Russian)]

Катанская В.М. (1981) Высшая водная растительность континентальных водоемов СССР. Методы изучения. Л., Наука, 187 с. [Katanskaya V.M. (1981) Higher aquatic vegetation of continental reservoirs of the USSR. Methods of study. Leningrad, Nauka, 187 p. (in Russian)] 
Макаревич Т.А., Мастицкий С.Э., Савич И.В. (2011) Перифитон на раковинах чужеродного моллюска Dreissena polymorpha Pallas: продукционные характеристики, вклад в бентификацию реципиентной экосистемы. Водоросли: таксономия, экология, использование в мониторинге. Бухарин О.В. (ред.) Екатеринбург, УрО РАН, с. 181-186 [Makarevich T.A., Mastitsky S.E., Savich I.V. (2011) Periphyton on the shells of the alien mollusk Dreissena polymorpha Pallas: production characteristics, contribution to the benthicification of the recipient ecosystem. Algae: taxonomy, ecology, use in monitoring. Bukharin O.V. (ed.) Ekaterinburg, UrB RAS, p. 181-186 (in Russian)]

Методы исследования органического вещества в океане (1980) М., Наука, 343 с. [Methods of studying organic matter in the ocean (1980) Moscow, Nauka, 343 p. (in Russian)]

Михеева Т.М. (1999) Альгофлора Беларуси. Таксономический каталог. Минск, БГУ, 396 с. [Mikheyeva T.M. (1999) Algoflora of Belarus. Taxonomic catalog. Minsk, BSU, 396 p. (in Russian and English)]

Михеева Т.М. (1989) Методы количественного учета нанофитопланктона (обзор). Гидробиологический журнал, 25 (4): 3-21 [Mikheyeva T.M. (1989) Methods of quantitative accounting of nanophytoplankton (review). Hydrobiological Journal [Gidrobiologicheskiy zhurnal], 25 (4): 3-21 (in Russian)]

Михеева Т.М., Ковалевская Р.З., Лукьянова Е.В. (2006) Показатели количественного развития и функционирования фитопланктона Нарочанских озер в разные периоды эволюции их трофического статуса. Состояние и проблемы продукционной гидробиологии: Сборник научных работ по материалам докладов на Международной конферениии «Водная экология на заре XXI века», посвященной столетию со дня рождения профессора Г.Г. Винберга. Москва, KMK, c. 199-211 [Mikheyeva T.M., Kovalevskaya R.Z., Lukyanova E.V. (2006) Parameters of the quantitative development and functioning of the phytoplankton of the Naroch lakes in different periods of the evolution of their trophic state. The state and problems of production hydrobiology: A collection of scientific papers on the materials of the reports at the International Conference «Water Ecology at the Dawn of the $21^{\text {st }}$ Century» dedicated to the centenary of the birth of Professor G.G. Vinberg. Moscow, KMK, p. 199-211 (in Russian)]

Остапеня А.П. (2007) Деэвтрофирование или бентификация? Озерные экосистемы: биологические процессы, антропогенная трансформачия, качество воды: Материаль III Междунар. науч. конф. Минск-Нарочь, 17-22 сент. 2007 г. Михеева Т.М. (ред.) Минск, с. 31-32 [Ostapenya A.P. (2007) Deeutrophication or bentification? Lake ecosystems: biological processes, anthropogenic transformation, water quality: Materials of the III Intern. Sci. Conf. Minsk-Naroch, 17-22 Sept. 2007. Mikheyeva T.M. (ed.) Minsk, p. 31-32 (in Russian)]

Остапеня А.П. (2014) Нарочанские озера: от эвтрофирования до бентификации. Научное наследие А.П. Остапени. Макаревич Т.А. и др. (ред.) Минск, БГУ, с. 258-263 [Ostapenya А.P. (2014) Naroch lakes: from eutrophication to bentification. Scientific heritage of A.P. Ostapenya. Makarevich T.A. et al. (eds.) Minsk, BSU, p. 258-263 (in Russian)]

Остапеня А.П., Ковалев А.А., Жукова Т.В., Михеева Т.М., Бабицкий В.А., Крючкова Н.М., Ковалевская Р.З., Костюкович С.Б., Инкина Г.А., Макаревич Т.А., Жуков Э.П., Иконников В.Ф., Самусенко А.М., Орловский А.Ф., Рачевский А.Н., Якушко О.Ф. (1993) Экологический паспорт озера Нарочь. Минск, Экомир Пресс, 95 с. [Ostapenya A.P., Kovalev A.A., Zhukova T.V., 
Mikheyeva T.M., Babitsky V.A., Kryuchkova N.M., Kovalevskaya R.Z., Kostyukovich S.B., Inkina G.A., Makarevich T.A., Zhukov E.P., Ikonnikov V.F., Samusenko A.M., Orlovsky A.F., Rachevsky A.N., Yakushko O.F. (1993) Ecological passport of Lake Naroch. Minsk, EcoMir Press, 95 p. (in Russian)]

Остапеня А.П., Ковалев А.А., Михеева Т.М., Бабицкий В.А., Жукова Т.В., Крючкова Н.М., Ковалевская Р.З., Костюкович С.Б., Инкина Г.А., Макаревич Т.А., Жуков Э.П., Иконников В.Ф., Самусенко А.М., Орловский А.Ф., Рачевский А.Н., Якушко О.Ф. (1994) Экологический паспорт озера Мястро. Минск, Экомир Пресс, 44 с. [Ostapenya A.P., Kovalev A.A., Mikheyeva T.M., Babitsky V.A., Zhukova T.V., Kryuchkova N.M., Kovalevskaya R.Z., Kostyukovich S.B., Inkina G.A., Makarevich T.A., Zhukov E.P., Ikonnikov V.F., Samusenko A.M., Orlovsky A.F., Rachevsky A.N., Yakushko O.F. (1994) Ecological passport of Lake Myastro. Minsk, EcoMir Press, 44 p. (in Russian)]

Остапеня А.П., Ковалев А.А., Михеева Т.М., Бабицкий В.А., Жукова Т.В., Крючкова Н.М., Ковалевская Р.З., Костюкович С.Б., Инкина Г.А., Макаревич Т.А., Жуков Э.П., Иконников В.Ф., Самусенко А.М., Орловский А.Ф., Рачевский А.Н., Якушко О.Ф. (1994а) Экологический паспорт озера Баторино. Минск, Экомир Пресс, 43 с. [Ostapenya A.P., Kovalev A.A., Mikheyeva T.M., Babitsky V.A., Zhukova T.V., Kryuchkova N.M., Kovalevskaya R.Z., Kostyukovich S.B., Inkina G.A., Makarevich T.A., Zhukov E.P., Ikonnikov V.F., Samusenko A.M., Orlovsky A.F., Rachevsky A.N., Yakushko O.F. (1994a) Ecological passport of Lake Batorino. Minsk, EcoMir Press, 43 p. (in Russian)]

Остапеня А.П., Жукова Т.В., Михеева Т.М., Ковалевская Р.З., Макаревич Т.А., Жукова А.А., Лукьянова Е.В., Никитина Л.В., Макаревич О.А., Дубко Н.В., Карабанович В.С., Савич И.В., Верес Ю.К. (2012) Бентификация озерной экосистемы: причины, механизмы, возможные последствия, перспективы исследований. Труды БГУ, 7 (1): 135-148 [Ostapenya A.P., Zhukova T.V., Mikheyeva T.M., Kovalevskaya R.Z., Makarevich T.A., Zhukova A.A., Lukyanova E.V., Nikitina L.V., Makarevich O.A., Dubko N.V., Karabanovich V.S., Savich I.V., Veres Yu.K. (2012) Bentification of the lake ecosystem: causes, mechanisms, possible consequences, prospects for research. Proceedings of $B S U$ [Trudy BGU], 7 (1): 135-148 (in Russian)]

Распопов И.М. (1973) Фитомасса и продукция макрофитов Онежского озера. Микробиология и первичная продукция Онежского озера. Л., Наука, с. 123-142 [Raspopov I.M. (1973) Phytomass and production of macrophytes on Lake Onega. Microbiology and primary production of Onega Lake. Leningrad, Nauka, p. 123-142 (in Russian)]

Руководство по химическому анализу поверхностных вод суши (1977) Л., Гидрометеоиздат, 541 c. [Guidance on the chemical analysis of surface land waters (1977) Leningrad, Gidrometeoizdat, 541 p. (in Russian)]

Унифицированные методы анализа вод (1973) М., Химия, 376 с. [Unified methods of water analysis (1973) Moscow, Khimiya, 376 p. (in Russian)]

Экологическая система Нарочанских озер (1985) Винберг Г.Г. (ред.) Минск, Университетское, 303 с. [Ecological system of Naroch Lakes (1985) Vinberg G.G. (ed.) Minsk, Universitetskoye, 303 p. (in Russian)]

Adamovich B.V., Zhukova T.V., Mikheeva T.M., Kovalevskaya R.Z., Luk’yanova E.V. (2016) Long-term variations of the trophic state index in the Narochanskie lakes and its relation with the major hydroecological parameters. Water Resources, 43(5): 809-817

Burlakova L.E., Karatayev A.Yu., Padilla D.K. (2006) Changes in the distribution and abundance of Dreissena polymorpha within lakes through time. Hydrobiologia, 571: 133-146 
Carlson R.E. (1977) A trophic state index for lakes. Limnology and Oceanography, 11: 361-369

Hillebrand H., Dürselen C.-D., Kirschtel D., Pollingher U., Zohary T. (1999) Biovolume calculation for pelagic and benthic microalgae. Journal of Phycology, 35: 403-424

Mastitsky S.E., Makarevich T.A. (2007) The zebra mussel shells as a substrate for periphyton. Abstracts of the $15^{\text {th }}$ International Conference on Aquatic Invasive Species. Nijmegen, The Netherlands, 23-27 September 2007. Nijmegen, Thieme Print4U, p. 121

Mills E.L., Casselman J.M., Dermott R., Fitzsimons J.D., Gal G., Holeck K.T., Hoyle J.A., Johannsson O.E., Lantry B.F., Makarewicz J.C., Millard E.S., Munawar I.F., Munawar M., O’Gorman R., Owens R.W., Rudstam L.G., Schaner T., Stewart T.J. (2003) Lake Ontario: food web dynamics in a changing ecosystem (1970-2000). Canadian Journal of Fisheries and Aquatic Sciences, 60: 471-490

Pomeroy L.R. (1974) The ocean's food web, a changing paradigm. Bioscience, 24: 499-504

SCOR-UNESCO Working group № 17 (1966) Determination of photosynthetic pigments in seawater. Monographs on Oceanologic Methodology. Paris, UNESCO, p. 9-18

Zhu B., Fitzgerald D.G., Mayer C.M., Rudstam L.G., Mills E.L. (2006) Alteration of ecosystem function by zebra mussels in Oneida Lake: impacts on submerged macrophytes. Ecosystems, 9: 10171028

Zhukova T.V., Radchikova N.P., Mikheyeva T.M., Lukyanova E.V., Kovalevskaya R.Z., Veres J.K., Medvinsky A.B., Adamovich B.V. (2017) Long-term dynamics of suspended matter in Naroch lakes: trend or intervention. Inland Water Biology, 3: 250-257 